\title{
RISK FACTORS INCREASING VULNERABILITY OF MIGRANT CHILDREN
}

\author{
Tanja MILOSHEVSKA, PhD \\ Ss. Cyril and Methodius University - Skopje, Faculty of Philosophy \\ Institute of Security, Defense and Peace \\ E-mail: tanja@fzf.ukim.edu.mk \\ Ana FRITZHAND, PhD \\ Ss. Cyril and Methodius University - Skopje, Faculty of Philosophy \\ Institute of Psychology \\ E-mail: anaf@fzf.ukim.edu.mk
}

\begin{abstract}
:
This article analyzes and highlights the major risk factors answerable for the exposure of migrant and refugee children to physical, psychological, and sexual violence and exploitation in the context of the ongoing migrant humanitarian crisis. This paper looks specifically at vulnerability to trafficking, abuse and exploitation, and the ways that particular migration contexts associated with irregular migration across the Western Balkan Route can affect risk and protective factors.

Precisely, we draw attention to the lengthy asylum process, long wait times, inadequate accommodation facilities for vulnerable children, inhumane living conditions, lack of security, ineffective humanitarian and insufficiently resourced child protection systems.
\end{abstract}

Key words: risk factors, migration, vulnerability, children, violence.

\section{Introduction}

In recent years, the flow of migrants and refugees children into Europe has significantly increased. This has primarily involved a dramatic influx of Syrian, Iraqi and Afghani migrants/ refugees who have moved through the Balkans (often referred to as "the Balkan route"12 (Bechev,

\footnotetext{
${ }^{12}$ The "Balkan route" is the path stretching from the Middle East to the European Union through Turkey and South East Europe, via the well-documented and sometimes deadly journeys by sea from Turkey to Greece, on to Macedonia and onward to the European Union, either via Serbia and Hungary or Serbia, Croatia and Slovenia.
} 


\section{Security}

2016) in their attempt to reach and resettle in northern Europe. Along the way and at various stages of their journeys and flights, many of these migrants and refugees children are exposed to different risks, vulnerabilities and exploitation, including, in some cases, human trafficking. And yet, to date, there has been limited empirical evidence of when, why and how vulnerability to human trafficking arises in mass movements of migrants and refugees and how new patterns of vulnerability and exploitation challenge established procedures for identification of and assistance to trafficking victims. More knowledge and evidence of these risk and vulnerability factors for migrant children are essential to better inform improved policy and programmatic responses in the fields of migration, asylum and human trafficking.

\section{The use of terms and definitions}

Migrant and refugee. A refugee is defined in the 1951 United Nations Convention relating to the Status of Refugees (and the 1967 Protocol relating to the Status of Refugees) ${ }^{13}$ as any person who: owing to well-founded fear of being persecuted for reasons of race, religion, nationality, membership of a particular social group or political opinion, is outside the country of his nationality and is unable or, owing to such fear, is unwilling to avail himself of the protection of that country; or who, not having a nationality and being outside the country of his former habitual residence as a result of such events, is unable or, owing to such fear, is unwilling to return to it. (Article 1.A.2)

According to the United Nations Convention relating to the Status of Refugees as amended by its 1967 Protocol (the Refugee Convention), a refugee is a person who is: outside their own country and has a well-founded fear of persecution due to his/ her race, religion, nationality, member of a particular social group or political opinion, and is unable or unwilling to return (UNHCR).

There is no universally accepted definition of migrant and disparate descriptions abound. Migrants may be defined by foreign birth, by foreign citizenship or by their movement into a new country to stay temporarily (sometimes for as little as a year) or to settle for the long-term. In addition, migrant is sometimes distinguished from, and sometimes includes, foreign nationals who are seeking asylum (Anderson and Blinder, 2017).

Recognising this complexity, in this paper we have used the combination term "migrant/ refugee", in an attempt to acknowledge and relate to both positions and the importance of problematizing these concepts and categories in an evolving social, political and economic context.

\footnotetext{
${ }_{13}$ The Convention entered into force on 22 April 1954 and it has been subject to only one amendment in the form of a 1967 Protocol, which removed the geographic and temporal limits of the 1951 Convention. The 1951 Convention, as a post-Second World War instrument, was originally limited in scope to persons fleeing events occurring before 1 January 1951 and within Europe. The 1967 Protocol removed these limitations and thus gave the Convention universal coverage.
} 
The meaning of vulnerability depends heavily on the context in which it is being used, and it is an "imprecise and contested concept" (Peroni and Timmer, 2013). For example, "vulnerable populations" are often referred to as specific groups, such as immigrants, refugees or the homeless (Ruof, 2004).

In the context of migration, IOM defines vulnerability as "the diminished capacity of an individual or group to have their rights respected, or to cope with, resist or recover from exploitation, or abuse" (IOM, 2016). It is characterized by "the presence or absence of factors or circumstances that increase the risk or exposure to, or protect against, exploitation, or abuse." The definition encompasses both individuals and groups, regardless of migration status. Immigration status can also have an impact on an individual's vulnerability or lack thereof, and undocumented persons are often found as susceptible to "multiple dimensions" of vulnerability (Hilfinger et al., 2015). In including the potential absence of risk factors, the definition makes room for the concept of protective factors. Just as there are certain factors that can contribute to making an individual more vulnerable, there are certain protective factors that can potentially contribute to reducing harm, exploitation and abuse. Understanding protective elements is important in order to go beyond a disempowering definition of vulnerability that denies an individual's agency to address his/her own vulnerabilities. Furthermore, such an understanding helps elucidate the ways in which individuals can be more or less vulnerable regardless of their membership of a particular group; women, children or refugees, for example.

Migrants highlighting conflict as a reason for moving and migrants who have departed from a country in conflict according to an international classification are more likely to be vulnerable to human trafficking and exploitation during their journey (Galos at all, 2017)

Migrants can be vulnerable to violence, exploitation and trafficking, by virtue of moving through situations where these types of practices are prevalent. The prevalence, in turn, being explained by the fact that there are not sufficient protective factors on the journey to ensure migrants' safety and that pre-existing risk factors may become more important.

\section{Profile of vulnerability}

In 2017 , over 171,300 people, including some 32,000 children and at least 17,500 unaccompanied and separated children (UASC) $)^{14}$, arrived in Europe through the Mediterranean Sea. This is almost two thirds less than in 2016, mainly as a result of reinforced border control and agreements between Libya and European countries aimed at stemming human smuggling and dangerous migrant crossings, particularly on the Central Mediterranean Route. Following the pattern from 2016, the majority of children arriving on the Eastern Mediterranean Route primarily to Greece were from Syria, Iraq and Afghanistan, while those on the move through the Central

\footnotetext{
${ }^{14}$ Children, as defined in Article 1 of the Convention on the Rights of the Child, who have been separated from both parents and other relatives and are not being cared for by an adult who, by law or custom, is responsible for doing so.
} 
Mediterranean were mainly from West Africa (Guinea, Ivory Coast, The Gambia, Nigeria, Eritrea and Bangladesh) (UNICEF, 2018).

Migrant children travel in a range of configurations. They may accompany family members, they may travel completely alone (so called "unaccompanied"15 child migrants) or they may be in the company of unrelated adults (so called "separated"16 child migrants). Some children embark on their migration accompanied but become unaccompanied or separated in the course of the journey.

Unaccompanied migrant children travelling towards Europe are reported to have reached an unprecedented number in 2016. Protection issues related to children on the migration routes or in reception and detention centres in the Balkans and Europe are increasingly reported by media and humanitarian organizations (see for example the recent: UNHCR, UNICEF and IOM, 2017).

The majority of recorded child migrant arrivals originate from three countries, Syria (27\%), Afghanistan (27\%), and Pakistan (24\%). The remaining 22 percent come from Iraq, Bangladesh, Algeria, Morocco, Iran, Palestine, and several other countries (EKKA, 2016). Actual figures of unaccompanied child migrant arrivals are likely to be considerably higher than those reported, as many unaccompanied children present themselves as adults or as accompanied during registration in order to avoid delaying their onward journey (Bhabha et al, 2016).

The time spent on the journey is a strong predictor of the probability to respond positively: the longer the journey, the more vulnerable to human trafficking and exploitation a child becomes. Moreover, children travelling alone are more likely than those travelling with a group of non-family people to report incidents.

Having a family member in the intended country of destination appears to be a protective factor for migrant children who travel without their families.

The findings related to the initial reasons for moving and to the level of conflict in the departure country are mixed. Results show that children are more vulnerable to human trafficking or exploitation on their journey if they left their countries of origin because of conflict/war or natural disasters. On the other hand, children who departed from a country in conflict according the UCPD/Prio classification, and travelling without family members, appear less vulnerable than children who left more stable countries.

The most vulnerable children travelling without their family members in terms of nationality follow the same pattern observed for the combined sample, with one important difference: Afghan children appear more vulnerable to human trafficking/exploitation than the rest of Afghans interviewed. Differences between children of different nationalities might be due to unobserved characteristics that relate to the environment of origin or other circumstances prior to departure,

\footnotetext{
${ }^{15}$ Adapted from the General Comment No. 6: Treatment of Unaccompanied and Separated Children Outside Their Country of Origin.

${ }^{16}$ Note: In the context of migration, children separated from both parents and other caregivers are generally referred to as unaccompanied and separated children.
} 
which are captured by the estimated country-level effects. Differences may also be due to how well children of certain nationalities are perceived and treated by host communities, communities they encounter in transit, as well as smugglers and those facilitating the journey (Eliza Galos at all, 2017).

The vulnerability associated with travelling completely alone and with travelling along the Western Balkan route clearly points to serious protection concerns for the increasing number of migrant children that arrived in Europe in 2016.

\begin{tabular}{|c|c|c|}
\hline \multirow{2}{*}{ 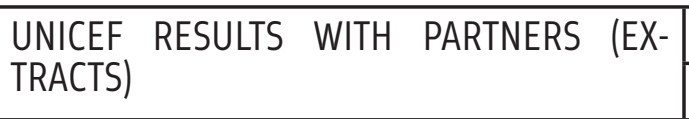 } & \multicolumn{2}{|c|}{ UNICEF and Partners Response } \\
\hline & Targets 2017 & Total Results 2017 \\
\hline $\begin{array}{l}\text { of at-risk children (incl. UASC) identified } \\
\text { through screening by outreach teams and } \\
\text { child protection support centres* }\end{array}$ & 10,350 & 17,917 \\
\hline $\begin{array}{l}\text { of children aged } 6-17 \text { including adolescents } \\
\text { participating in structured education activi- } \\
\text { ties }\end{array}$ & 11,850 & 10,152 \\
\hline $\begin{array}{l}\text { of frontline workers trained on child protec- } \\
\text { tion standards/child protection in emergen- } \\
\text { cies }^{* \star}\end{array}$ & 3,975 & 6,353 \\
\hline \multicolumn{3}{|c|}{$\begin{array}{l}\text { *Combines results in Turkey, Greece, Bulgaria, Macedonia, Serbia and Italy } \\
\text { ** Combines results in Greece, Italy, Bulgaria, Serbia and Macedonia } \\
\text { *** Combines results for Bulgaria, Croatia, Germany, Greece, Italy, Serbia and Macedonia }\end{array}$} \\
\hline
\end{tabular}

In 2017, a total of 280 children, including 85 unaccompanied and separated children, benefitted from psychosocial support and referral in UNICEF-supported Child and Family Support Hubs (Blue Dots) in Gevgelija and Tabanovce. In addition, 207 school-age children attended UNICEF-supported structured non-formal education activities and 305 young children and their mothers received early and young child feeding assistance in UNICEF mother-and-baby corners. A total of 541 children in the transit and asylum centres, as well as children on the move, received season-appropriate clothes and other essential items. UNICEF also trained 164 social workers on topics related to child protection and work with adolescents in emergencies, thus ensuring preparedness and sustainability of services for similar future situations.

To address the pressing mental health issues experienced by refugee and migrant children and families stranded for extended periods of time in the Transit Centres, UNICEF prioritised mental health in its programming in 2017. For the most vulnerable cases this translated into early interventions, conducted by experienced psychologists identified in collaboration with the Macedonian Chamber of Psychologists. A first of its kind national manual for promoting the mental health of children, which can be adapted to all emergency settings, was also developed (UNICEF, 2018). 


\section{Security}

The visibility (and invisibility) of trafficking vulnerability is also influenced by the capacity as well as perceptions, assumptions and biases of those frontline responders who are responsible for victim identification. Unaccompanied minors are, in theory, a visible group with obvious risks and vulnerability to exploitation due to their age/maturity and unaccompanied status. But, as one service provider noted of her work with vulnerable children, some older children and youth may not be easily recognizable as children and their vulnerabilities and risk of trafficking exploitation may be overlooked. By virtue of what they have endured as migrants/refugees, they may appear older than they are and perceived as adults, rendering invisible their vulnerability and the many risks they have and may encounter. This is but one example of trafficking risk that may currently be invisible and more attention is needed as to how to make visible the range of trafficking vulnerabilities within this migrant/refugee population.

\section{Risk factors}

Specific risk factors increasing migrant children's vulnerability were identified in the studied geographic areas. These factors directly and detrimentally impact the physical and psychological well-being of migrant children by disrupting their habitual protective environments and by generating challenging new family dynamics (Save the Children).

The paper highlights the following major risk factors:

\section{Lack of capacity/Insufficient number of specialized facilities for children}

The circumstances faced by migrant children largely depend on the facility where they are housed. However, although third-line facilities are the most suitable and beneficial settings for migrant children, these facilities have a severely limited capacity. Consequently, many migrant children are held in prolonged detention or among a larger adult migrant population, in contexts that aggravate their exposure to perilous living conditions and violence.. Lack of proper shelter, poor protection standards and limited reception capacity remain critical issues, particularly in Italy, Greece and Spain, where both accompanied and unaccompanied children are kept for extensively long periods in hotspots and first reception centres, often in detention-like conditions. (UNICEF, 2018).

While accompanied children, traveling under the protection of caregivers, may appear to be at a lower risk for becoming victims of violence in the camps, the hardships created by the deplorable living conditions can increase their levels of risk (ECPAT, 2006).

\section{Risky living conditions}

Since the onset of the humanitarian crisis, migrant living conditions have been characterized as deficient and precarious, failing to meet minimum health and safety standards and subjecting migrants to inhumane treatment (Carvalho and Pierigh, 2016). Some camps offer 
protected living areas for families; however, since space is severely constrained, many families are forced to live in tents among the general adult population without any protection or separation. Inside the protected areas, families are forced to share their living space with unfamiliar families. Other camps offer unaccompanied children separate living areas with more protective tents or structures. However, according to an NGO worker in Athens, "These places are open and accessible to everyone, especially during the night." According to another NGO worker, "Some camps have 'Safe Spaces' for children that are supervised 24 hours a day by members of NGOs (Digidiki, Bhabha, 2017). However, it depends on the camp you are in. Some children are lucky and some are not." Structural factors, such as a lack of night lighting in camps, increase the risk of violence against women and children (Emmanouilidou, et al, 2017). However, despite recent efforts to improve living conditions and to provide fundamental services, camps continue to struggle to meet migrants' basic needs.

\section{Weak and insufficiently resourced child protection systems}

Frequently migrants are unaware of their rights, opportunities and legal options, and are left to fend for themselves in centres without information or legal support. This has led to serious threats to their mental health, increased likelihood of absconding from the formal reception system, and risky behaviours and negative coping strategies (including transactional sex). Access to services such as education, health, and other social services remain challenging in many locations, thus hampering children's development and delaying their social inclusion. This is particularly true for children with or without families in first reception facilities, children from so called 'safe third countries' (e.g. in the Western Balkans) or countries with low asylum recognition rate. (UNICEF, 2018).

This has become starkly relevant in the context of the massive migration and refugee flow that has unfolded in the Balkan region over the past two years (Brunovskis and Rebecca Surtees, 2017). And in these emergent and specific circumstances, human trafficking does not necessarily follow the same patterns as it has previously, nor even follow commonly understood vulnerabilities in general trafficking discourse. Vulnerability and risk take different forms and mean different things for people who are on the move and indeed in flight as compared with people who are vulnerable within their own communities and in countries where they have legal status and access to rights and protections. Human trafficking within a context of the massive and rapid movement of migrants and refugees and widespread human smuggling may not be easily recognisable as human trafficking. This is both because it may "look" different from "typical" forms of trafficking and because the circumstances of mass migration/flight (i.e. swift passage through a country, mixed nationalities, lack of a common language, lack of trust in authorities) make it difficult for frontline responders to gain an immediate and thorough knowledge of each individual's circumstances and vulnerabilities, including when these rise to the level of human trafficking.

Furthermore, the boundaries between human trafficking and human smuggling are already challenging to implement in practice on the frontlines of identification and intervention (Skilbrei 


\section{Security}

\& Tveit, 2008) and may become less clear in cases where migrants/refugees have been subjected to violence and/or extortion by smugglers, which may or may not meet the criteria for trafficking.

\section{Exposure to violence}

The forced cohabitation of hundreds of migrants of different cultural backgrounds, genders, and ages in inhumane conditions while facing an uncertain future and potential deportation has predictably generated anger, frustration, and hostility-sentiments that often spill over into acts of violence. Because of inadequate protective systems, women and children, who make up almost a half of the migrant population, face a particularly high risk of such violence.

\section{Delays in the asylum and relocation process-trigger for physical violence}

Young children and adolescents witness these acts of violence or, when caught in the crossfire, become its victims; some imitate violent acts themselves by participating in the riots. These incidents of violence have a severe psychological impact on children, reviving in them adverse experiences of violence from their past. This has an immediate impact on their physical and mental health," reports a psychologist working in one of the camps (Digidiki, Bhabha, 2017).

Children with disabilities and children who have experienced trauma and abuse often lack vital specialised services. Unaccompanied and separated children, who are close to adulthood, also face numerous barriers and challenges in accessing education (language and vocation training) and protection due to their adolescent age, slow asylum procedures or overstretched social welfare and guardianship systems. Return and repatriation of refugees and migrants is also high on the European political agenda, and it is the responsibility of governments to adopt and/or improve safeguards for children and carry out a full best interest's determination during the assessment of decisions to return children to their country of origin. (UNICEF, 2018).

"Violent episodes were triggered when migrants learned that their asylum claims had been rejected. Their despair led many immigrants to try and hurt themselves; some hit their heads against the walls or tried to rip their hair out or cut their veins. They exhibit violent behavior towards their children also by pushing them and kicking them when they're on the floor" (EEDD, 2016).

\section{Sexual violence}

Weak or non-existent protective and legal structures inside camps exacerbate the risk of violence among migrants. Children's inherent vulnerability and dependency on others, places them at a heightened risk for sexual violence. Unaccompanied children are at a heightened risk, as they can be victimized by adults and, for those held in detention facilities, by other unaccompanied children. The coexistence of dozens of children of various ages from different cultures and ethnic and socioeconomic backgrounds creates significant power differentials. Research on sexual violence has shown that violence is a commonly used method to assert power and dominance in a social setting (Warburton, 2016). 
Having endured the risks of sexual violence or having experienced sexual violence during their journey, migrant children suffer from the fear of sexual abuse in a place that should have guaranteed them safety and protection. This fear generates mistrust in the protection systems and legal paths to migration and may eventually force migrants to seek new and dangerous paths to a safer destination (UNICEF, 2016).

\section{Psychological violence}

Physical and sexual violence are often accompanied by psychological violence. Many participants noted that migrant children routinely fall victim to the influence of migrants engaged in criminal activities and gangs. "They [mafia gangs] take humiliating photos of children and then threaten the children with sending the photos to their families back home. This could be even worse than a violent act itself. Even if children survive physical or sexual abuse at their hands, the prospect of having their families know about this is even more devastating," notes a research participant working in a camp. Another psychologist highlights the fact that blackmail is very common inside the camps, affecting both adult and child migrant populations. "They try to accept the situation and hide it from their families and then someone threatens to humiliate them back home, in one or another way. How can they overcome this threat? They have to obey them [the perpetrators] to reduce the risk of blackmail. But this never stops. It is a vicious cycle." This kind of violence damages the already fragile mental health of children, turning them into easy prey for further physical and sexual violence and exploitation (Digidiki, Bhabha, 2017).

\section{Reflections}

Risks are increasingly complex and interrelated. Failure to understand these linkages can deepen and widen humanitarian crises as well as ensure that development remains unsustainable.

The 2030 Sustainable Development Goals (SDGs) reflect a growing international awareness of the impact and importance of current global migratory movements, and mark the first inclusion of migration in the global development framework. The goals reflect a consensus regarding the need to pay more attention to the risks encountered by all types of migrants moving along dangerous routes, often irregularly, and to the measures needed to manage these movements. The 2016 World Humanitarian Summit in Turkey also reflected this growing global awareness of the dynamics between migration, displacement and crisis situations. The need to address displacement and the vulnerabilities of migrants formed part of its five core responsibilities (WHS, 2016), and the SDGs also recognize the negative impact of forced displacement and humanitarian emergencies on the development of countries and their citizens.

Along with the focus on "safe migration" and "well-managed migration policies", three other goals potentially relate to "unsafe migration", particularly with regard to trafficking in persons (TiP), exploitation and abuse of migrants:

SDG 5.2: Eliminate all forms of violence against all women and girls in the public and private spheres, including trafficking and sexual and other types of exploitation. 
SDG 8.7: Take immediate and effective measures to eradicate forced labour, end modern slavery and human trafficking and secure the prohibition and elimination of the worst forms of child labour, including recruitment and use of child soldiers, and by 2025 end child labour in all its forms.

SDG 16.2: End abuse, exploitation, trafficking and all forms of violence against and torture of children.

Our findings complement earlier research on sexual violence and exploitation during humanitarian crises.

We disclose the durable impact of exploitation and abuse on the psychological health of migrant children, and show how these result in a cascade of socio-psychological symptoms with profoundly deleterious impacts on children's resilience, self-esteem and long-term well-being.

As the migrant and refugee situation in the Balkans carry on to develop, vulnerability and risk possibly will modificate and evolve, converting into another forms of human trafficking. The dynamic nature of forced and voluntary migration requires that reactions to vulnerability and need amongst migrants and refugees must be flexible and rapidly adjust to new and changing circumstances, including as they relate to other dynamic issues like human trafficking.

\section{References}

1. Anderson, B., Blinder, S. (2017). Who Counts as a Migrants? Definitions and their Consequences. Available at: Oxford: UK: http://www.migrationobservatory.ox.ac.uk/resources/briefings/ who-counts-as-a-migrantdefinitions-and -their-consequences/

2. Anette Brunovskis, A., Surtees, R. (2017). Vulnerability and exploitation along the Balkan route: Identifying victims of human trafficking in Serbia, Fafo Report, 0 slo.

3. Bechev, D. (2016). Europe's Refugee Crisis and the Balkans. Available at: http://www. shargforum.org/2016/06/08/europes-refugee-crisis-and-the-balkans/

4. Bhabha et al. (2016). "Children on the Move: An Urgent Human Rights and Child Protection Priority."

5. Carvalho, R., Francesca Pierigh, F. (2016). "Have you seen this camp?" ECRE \& AIRE Centre. Available at https://onhold.exposure.co/have-you-seen-this-camp.

6. Digidiki, V, Bhabha, J (2017). Emergency within emergency-The growing epidemic of sexual exploitation and abuse of migrant children in Greece, FXB Center for Health and Human rights, Harward University, Boston, USA.

7. ECPAT (March, 2006). Protecting children from sexual exploitation and sexual violence in disaster and emergency situations, Ratchathewi, Bangkok: ECPAT International.

8. EKKA. (2016). Situation Update:Unaccompanied Children(UAC) in Greece, Available at: http:// data.unhcr.org/mediterranean/regional.php

9. Emmanouilidou, H et al., (2017). "Conditions in refugee camps: the case of Schisto," Network for Children's Rights. 


\section{Secuurity}

10. Galos E, at all, (2017), Migrant Vulnerability to Human Trafficking and Exploitation: Evidence from the Central and Eastern Mediterranean Migration Routes, International Organiztion for Migration (IOM), Switzerland, Geneva.

11. Hilfinger M. et al. (2015). The impact and implications of undocumented immigration on individual and collective health in the United States. Nursing Outlook, 63(1):86-94. Available at: 10.1016/j.outlook.2014.11.004.

12. United Nations High Commissioner for Refugeers (UNHCR), Convention and Protocol relating to the Status of Refugees. Available at: http://www.unhcr.org/protection/ basic/3b66c2aa10/conventionprotocol-relating-status-refugees. html

13. International Organization for Migration (IOM).(2016). Understandingmigrants'vulnerability: A framework for analysis and programming. IOM, Geneva.

14. Jacqueline B. et al., (2016). "Children on the Move:AnUrgent Human Rights and Child Protection Priority." Boston: Harvard FXB Center for Health and Human Rights. Available at: https:// fxb.har vard.edu/reports/

15. Jane Warburton (2016). "Preventing the sexual exploitation of children: A mapping of practice and interventions," ECPAT International Journal, 11.

16. Office of the United Nations High Commissioner for Refugees (UNHCR), (2017) UNICEF and International Organization for Migration (IOM) 2017 Refugee and migrant children including unaccompanied and separated children - in the EU: Overview of trends in 2016. Factsheet, April. Available at: https://data2.unhcr.org/en/documents/download/55971

17. Peroni, L., A. Timmer. (2013). Vulnerable groups: The promise of an emerging concept in European Human Rights Convention Law. International Journal of Constitutional Law, 11(4):1056-1085. Available at: 10.1093/icon/mot042.

18. President of the Association of Greek Judges and Public Prosecutors for Democracy and

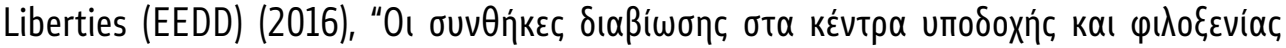

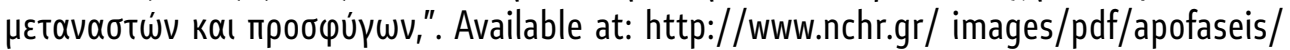
prosfugesmetanastes/kentra_filoxenias_autopsia.pdf

19. Ruof, M.C. (2004) Vulnerability, vulnerable populations, and policy. Kennedy Institute of Ethics Journal, 14(4):411-425. Available at: 10.1353/ken.2004.0044.

20. Save the Children, Physical violence and other harmful practices in humanitarian situations. Minimum Standard for Child Protection in Humanitarian Action: CPMS 8. Available at: http:// resourcecentre.avethechildren.se/sites/default/files/documents/tdh pvohp formatted. pdf.

21. Skilbrei, M.-L.,.,Tveit, M. (2008). Defining Trafficking through Empirical Work: Blurred Boundaries and their Consequences. Gender, Technology and Development, 12(1), 9-30. Available at: $10.1177 / 097185240701200103$.

22. UNHCR, Convention and Protocol relating to the Status of Refugees, Communications and Public Information Service, UNHCR, Geneva, Switzerland, Available at: http://www.roadsto-refuge.com.au/whois/whois definitions.html

23. United Nations Committee on the Rights of the Child (CRC), (2005). 


\section{Secuurity}

24. UNICEF (2016). Refugee and Migrant Crisis in Europe, The right of the child to family reunification.

25. Available at: data.unhcr.org/mediterranean/download.php?id=1169

26. UNICEF (2018). Refugee and Migrant Crisis in Europe Humanitarian Situation Report \# 26.

27. World Humanitarian Summit (2016). Available at: https://www.agendaforhumanity.org/. 